\title{
The heritage prospective and urban expansion in capital cities: old defence sites in Muscat, Oman
}

\author{
M. A. K. Al-Belushi \\ Department of Archaeology, College of Arts and Social Sciences, \\ Sultan Qaboos University, Sultanate of Oman
}

\begin{abstract}
Urban expansion is currently a major trend in capital cities throughout the developing world. This trend is playing a major role in changing the historical fabric and contexts of those cities. Predictably, the built heritage of Old Muscat is also being affected by urban expansion and development. This paper investigates the nature of the relationship between preservation of cultural heritage and urban expansion through a study of the way the defence sites of Muscat - the capital city of Oman- are managed. The paper investigates the points of collaboration and conflict between cultural heritage and urban expansion in Old Muscat, and looks at how a balance may possibly be maintained between them. The paper shows that various types of defence sites such as forts, castles, towers, walls, and gates represent an important part of the identity and history of the place. It also shows that although the defence sites of Old Muscat have received a relatively large amount of attention from urban planners, the management and utilization of these sites is questionable. It also shows that the modernization of the city, and the associated phenomenon of urban primacy, have both led to a cultural shift that is affecting people's perception of the defence sites.

Keywords: Muscat, Sultanate of Oman, built heritage, defence sites, urban expansion, urban primacy, heritage management.
\end{abstract}

\section{Introduction}

Muscat is the capital city and seat of government of the Sultanate of Oman. The section referred to as Old Muscat is built around a horseshoe shaped natural 
harbour dominated by rugged and barren dark brown mountains, which are dotted with old defence structures. It is the most important historic city in Oman. Muscat has a large number of archaeological and historic sites, the oldest of which dates back to the sixth millennium BC Its built heritage indicates its cosmopolitan history, thanks to Muscat's strategic location, which has historically linked East with West. The old defence sites of Muscat testify to the influences and interests of people who have inhabited, visited, or invaded the place throughout the centuries. Throughout time, the forts and the city wall, with its towers and gates, have constituted the most striking landmarks of Muscat. In addition to their original defensive functions, these fortifications represented, in the past, the seat of administrative and judicial authority.

However, in the early 1970s when His Majesty Sultan Qaboos came to power, these defence sites ceased to play a role in government as a result of the new era of unprecedented political, social, and economic development which Oman entered at that time [1, 2]. Swift urban expansion resulted from this development and altered various facets of life in Old Muscat, among the most important of which was Muscat's built heritage. Newly emerged employment facilities, and improved modern infrastructure led people to leave their settlements in Old Muscat in favour of newer nearby residential areas. As a consequence, a considerable portion of the traditional architectural elements of the old quarters eventually eroded, and their associated historic defence sites started to lose their status.

Because of its status, Muscat has received special treatment in terms of preservation and conservation. Over the previous four decades, Old Muscat has undergone several rehabilitation and renovation projects, a substantial portion of which targeted the restoration of its defence structures. Despite the great benefits gained from such projects, the defence sites of Muscat do not represent more than the historic backdrop of the place, and have long since ceased to be an integral part of the peoples' daily lives. This raises a question about the extent of the change that has occurred to both the perception and sentimental value assigned to the defence sites by local people.

\section{Muscat}

The main historic events of Muscat are imprinted in its cultural remains. The earliest archaeological evidence discovered in the vicinity of Muscat dates back to the sixth millennium BC, to the coastal settlement site of Ras Al-Hamra, which is a few kilometres from Old Muscat [3]. The recovered materials from this site and related sites in the adjacent areas of Al-Sharqiyah suggest ancient maritime contacts with the great cultures that flanked Oman such as those of the Indus Valley and Ilam, and Mesopotamian civilisations.

In the first century AD, Muscat started to become known as an important trading port connecting the East and West. The Greek geographer, Ptolemy, referred to Ras Al-Hamra as Cryptus Portus (Hidden Port). Throughout the ages, Muscat has attracted people from different origins and therefore the city has been exposed to different cultures throughout its history. It was ruled at some periods 
of its history by various indigenous tribes as well as by foreign powers such as the Persians and the Portuguese [4]. In the third century AD, Muscat entered into a period in which it was ruled by the Sasanids and, during the seventh century, its people converted to Islam.

The city continued in the following centuries to be an important port. In the early years of the sixteenth century, while it was under the rule of the Persians, Muscat was conquered by the Portuguese [4]. During their century-long occupation of Muscat, the Portuguese built the famous twin forts Al Jalali and Al Mirani, in addition to other forts and towers outside Muscat. The emerging power of al Ya'ariba Imamate (1625-1744) transferred the power of the Portuguese back to the Omanis. The expulsion of the Portuguese from Muscat enabled the Omanis to command the trade routes of the Indian Ocean.

As a result of civil war, the Ya'ariba Imamate came to an end, giving the Persians the opportunity to conquer Oman again in 1737. However, Omani resistance led to the expulsion of the Persians and eventually to the election of Imam Ahmed bin Said, the founder of the Al Bu Sa'id Dynasty which has ruled Oman ever since [4]. The new imam moved the capital from the interior to Muscat. As a result of the peace and prosperity that followed, the naval and military supremacy of the new dynasty extended the rule of the Omanis to considerably large sections of the East African coast and led to Muscat becoming the unrivalled capital of trade in the Indian Ocean.

During the second half of the nineteenth century, the country underwent instability because of conflicts between the Sultan of Muscat and Oman, and the tribes of the interior. The conflicts, which continued into the 1950s, isolated Oman from the rest of the world, and it entered into a period of decline. The accession of His Majesty Sultan Qaboos bin Said in 1970 marked the beginning of a modern era in Oman, which has been characterised by an extensive programme of urban development and infrastructural renewal, of which Muscat has naturally been the focus [5].

\section{Old defence architecture in Muscat}

The old defence sites of Muscat have been influenced by its strategic location as an important seaport connecting the trade routes between Arabia, India, Europe, and East Africa. The Portuguese trade domination of the Indian Ocean, which occurred between 1507 and 1650, and their control of Muscat have directly shaped the distinct characteristics of the fortifications in Muscat. The resistance and opposition of the Omanis forced the Portuguese to build a defensive system to protect the immediate area surrounding the harbour of Muscat, which became their stronghold. They selected the most commanding position of the surrounding barren mountains of the harbour to build their two forts of Al-Jalali and Al-Mirani and their supportive watchtowers [6]. This planning, which took into account the exceptional natural defences afforded by the mountains and the sea, endowed the town with impregnability. To reinforce the town they also built a mud wall with gates and watch towers. 
Muscat is characterised by its sheltered harbour. This harbour played a major role in the establishment of the city thanks to its distinct natural defence characteristics. Most of the fortifications of Muscat that overlook this harbour are of Portuguese origin. This harbour also represented an "important port of call for shipping and, with its wells in nearby Tuyan, a source of freshwater supplies" [6]. The charm and strategic location of this harbour and its high incidence of use by traders are reflected today by hundreds of ship names that can be seen painted in white on the cliffs around the harbour. The oldest of these names dates back to 1876 [7].

Al-Mirani Fort was built prior to the Portuguese invasion. Due to its strategic location on the harbour of Muscat, the Portuguese rebuilt it in 1587 into a strong fort with stronger defensive structures. The fort became the first in Oman to use cannons. In the eighteenth century, the founder of the Al Busaid Dynasty, Imam Ahmed bin Said, and his successors reinforced and extended the structures of the fort. In addition to their defensive functions, the cannons of this fort were also used to salute or warn ships entering the harbour, as well as to herald the end of the day and the closing of the town gates after the sunset [8]. Today, the fort is used as a barracks for the Sultan Armed Forces.

Facing Al-Mirani, Al-Jalali Fort was built by the Portuguese on top of an isolated hill overlooking the harbour of Muscat from the east. Its construction was completed in 1588. Its front consists of two main towers linked by a curtain wall. With the exception of steps cut into the rock along the harbour which end near one of the towers, the fort is isolated and unreachable from the mountain side. Along with Al-Mirani, it represents the most prominent landmark in Muscat. Al Jalali Fort was used until the 1970s as a prison. This prison was described by Colonel David Smiley, who commanded the Sultan's Armed Forces at Muscat, as 'a veritable hellhole' housing about a hundred inmates who had been herded indiscriminately together [8].

Following their defeat at Hormuz by the Persians in 1622, the Portuguese built Muscat's wall and gates to supplement their earlier fortifications [6]. The wall, with its towers, was built in 1625. It is shown in the map drawn by Pedro Barretto de Resende in the seventeenth century. The wall is 750 metres long and once bounded the city from the east and south. It was originally built to protect the area occupied by the Portuguese and to separate it from the local settlement. It contains four gates, Bab Matha'ib, Bab Al Kabir, Bab Waljat and Bab Al Saghir, which used to provide the only access to the fortified city. Until 1970, these gates were closed from dusk until dawn [6]. It seems that the previous custom of closing the gates of the city three hours after sunset, which was announced through the daily firing of three shots, and the obligation to take a lamp while going from one place to another within the walled area, is a continuation of a tradition started during the Portuguese period [9]. Amongst the towers of this wall is Kebritta Tower, which remains unchanged from years past [6]. This tower was the last Portuguese stronghold against Imam Sultan bin Sayf al Yarubi, who finally expelled the colonising power from Oman [10]. 


\section{Urban expansion and primacy of Muscat}

With the accelerated pace of Oman's development over the last 40 years, and the steady growth of its population, it was inevitable that Muscat's urban expansion would become an issue. Due to the prosperity of the city, a large number of people from other parts of the country have migrated to Muscat. Today, Muscat Governorate represents the main urban area in Oman [11]. Urbanisation as a phenomenon started to take place in the early 1970s, and the total urban expansion has multiplied since then. At its beginning, population growth was limited mainly to the settlements of Old Muscat and Muttrah. After that it extended dramatically and now covers other surrounding areas. By the early 1980s, the rate of urban expansion had increased so much that the population had encroached upon most of the areas around Old Muscat that were suitable for settlement. In more recent years, the area's population has increased sharply. The 2010 Census showed that the Muscat Governorate represents about 28\% the total population of the Sultanate, while it was about 23\% in the 2003 [11]. This increase has been paralleled by a growth in the area's infrastructure and services.

The early five-year development plans, upon which the government embarked in 1976, concentrated mainly on developing Muscat. As has been the case in other similar capital cities in developing countries, the emphasised investment of infrastructure in Muscat has led over time to turning it into a primate city with a high and unrivalled concentration of urbanites. According to the 2003 Census, Muscat received more than $80 \%$ of the internal migration of Oman [11].

Because of the attractiveness of the new amenities and infrastructure which started to appear on the periphery of Muscat in the early 1980s, many of the inhabitants of Old Muscat started to migrate to the newly established residential areas. This migration was also catalysed by the morphological characteristics of the area that limited the possibility of expanding the original settlement. The topography of Old Muscat played a major role in limiting its capacity to accommodate the growing number of people with their new demands; hence, it directed the government to search for a planning philosophy that could integrate the status and role of the old town with the new changes in the socio-economic and political contexts.

\section{Early town planning approaches}

The extensive and swift development of the early years of the 1970s threatened the traditional architectural fabric of Old Muscat and, hence, directed the government to search for a planning approach that would preserve the identity of the place. Some of the town planning approaches adopted by the government in that period can be seen today imprinted in the urban fabric of Old Muscat. In her book The Architecture of Oman, Salma S. Damluji summarised the work of the two architectural practices of John R. Harries, Architects, Design and Planning Consultants, and Makiya Associates, which the Omani government commissioned in 1970 and 1973, respectively, to prepare their planning proposals for the development and extension of Muscat and Muttrah [5]. Taking 
into consideration the social and cultural contexts, both practices focused on the importance of integrating the preservation of the building heritage of Muscat in the proposed urban development plans.

The approach of the Makiya Associates centred on the notion that the indigenous architecture of Old Muscat should be kept intact and that the function of the place should be restricted to that of a nominal capital city, and that the state administrative departments should be relocated to the surrounding new metropolitan area which were then being developed [5]. John Harris Architects proposed that Old Muscat should continue to be the seat of government and should be rehabilitated as a cultural centre with severely restricted commercial development [5]. Harris Architects also proposed the preservation of the old buildings and the development of the Old Muscat and its neighbouring areas as a tourist centre [5].

Both proposals, to a large extent, influenced the development plans that have been adopted since then by the government, despite the fact that the defence structures of Old Muscat had not been the main issue for consideration in these proposals. However, most of the defence structures of Old Muscat have been retained through a number of restoration projects.

\section{Discussion}

Based on the above facts, the following discussion will focus on a number of main issues related to the collaboration and conflicts between the preservation of defence heritage sites and urban expansion in Old Muscat.

\subsection{Development versus conservation}

The tension between development and heritage conservation is not an issue that is unique in a revitalised historic city like Muscat. Problems related to land use, the local economy, and the consumption of historic assets all impose substantial pressures on the distinctiveness and attractiveness of any city [12].

Pressures of development on the historic architectural fabric of Old Muscat started in the 1970s as a consequence of ambitious national development plans, which was the first of its kind in the history of Oman. Urban expansion, one of the main features of this development, dominated the townscape and left limited opportunities for Oman's traditional lifestyle or architecture to persist. The reasons behind this disappearance include the limited spaces available in the old city, the difficulty of introducing modern utilities infrastructure to the old quarters, the lack of convenient accessibility of Old Muscat to services and utilities, and indeed, the attractiveness of the new areas as opposed to Old Muscat.

These factors taken together led to the establishment of new settlements outside the old city. The establishment of the new settlements in the nearby spacious areas of Ruwi, Darsit, Al-Qurm, Al-Khuwair, Madinat Qaboos, and AlAzaibah all played a major role in the abandonment of the old houses of Muscat, a change which also occurred in the other parts of the country. Planners 
confronted this change with different management approaches to both the domestic and the defensive architectural fabrics. Due to their nature, the old quarters that are located inside the walled area of Muscat like Waljat, with its historic houses and diplomatic buildings, received better treatment than those located outside the wall. Parts of the walled area, such as the houses of the merchants and the building of the British Embassy, have been adapted and remained in use until the mid-1990s. This careful treatment can probably be attributed to the good physical state of the buildings, their architectural aesthetic value, and their tangible impact on the history of the city. However, these buildings, although used into the 1990s, have since been replaced by newer buildings. Similarly, due to their good physical state, a number of houses outside the walled areas have been restored and adapted, such as the Bait Al-Zubair and Bait Muzna, which have been converted into museums and galleries.

On the other hand, the small houses that belonged to local people were treated differently. The governmental organization concerned with the preservation of the historic environment, the Ministry of Heritage and Culture, did not put into practice the concept of listing these houses in the national preservation list even though the 1980 National Heritage Protection Law (NHPL) stipulates the preservation of the buildings' groups [13]. This was probably due to a number of reasons among them being the poor physical state of these houses, their nontraditional architecture, the irregular and random distribution of these houses, and their possible lack of architectural aesthetic value. Additionally, and possibly most importantly, those houses were not in harmony with what was a new, modern, and comparatively magnificent architectural fabric. This raises questions about the extent to which these reasons are acceptable, and the validity of granting planners an excuse to eradicate part of the city's history.

The abrupt and drastic change in the social, economic, and political contexts of Muscat also led to a change in the intrinsic value of its old defence sites. This has, since the early years of the 1970s, confronted city planners as well as heritage organizations with the dilemma of which structures to select for preservation and which could be deemed acceptable to discard. It has also faced them with the challenge of how to strike a balance between preserving these remains and presenting them in a sensible way. The limited space available in Old Muscat played a major role in the intention of the government to restructure nearly the entire area. This has led to the elimination, or at least the rebuilding (but not restoration) of important parts of the historic defence system of the old city, such as the towers and the city wall.

The complexities surrounding the management of the defence sites of Muscat stem from the fact that they have been thought of as separate entities by urban planners. Defensive structures like the forts and gates were not constructed in isolation of the old houses and amenities attached to them as they appear to exist today. This segregation can be observed most obviously in both Al-Jalali and AlMirani forts. Although the two forts have been restored more than one time since the 1970s, their current use, presentation, and accessibility are limited. Preservation as a process as David Baker describes it is 'a matter for ethical frameworks, technical procedures and managing threats from economic 
development or natural decay, [while] presentation focuses upon communication, education, marketing and visitor management' [14]. The scope of preserving the defence sites of Muscat should be stretched to encompass all the interrelated contexts of the historic environment that are associated with these sites.

The old defence structures of Muscat consist of two parts. The first part consists of the forts and towers that are on the summits of the mountains, while the second consists of the city wall and its associated gates and land towers. The development plans which started in the 1970s and extend to the present day have not had much effect on forts and towers because of their relative remoteness from places that can be developed. That is why their shapes and characteristics have not changed much. From the structures depicted in De Resende's drawings of 1635 [15], it can be observed that these structures have remained largely unchanged into the present. The only changes that can be detected are related to the restoration projects that these structures have undergone since they were built.

On the other hand, the second type of defence structures, the city wall and gates, have undergone many changes for a number of reasons, including (a) their proximity to domestic buildings; (b) their easy accessibility; (c) their weak structure as compared to that of the forts; and (d) their location in an area where change cannot be avoided by urban planners. For instance, the gates of the city were enlarged as they were preventing ease of vehicular access to the central part of the city.

\subsection{Statutory control}

Like other historic elements in Oman, the historic defence structures of Old Muscat are legally controlled by the National Heritage Protection Law (NHPL) [13]. Additionally, these structures receive a supplementary statutory protection from a number of cross-references that appeared in other related legislation and regulations dealing directly or indirectly with the preservation and conservation of the country's heritage.

Despite the nationwide scope of the NHPL, the historic defence structures in Old Muscat received a different protection scheme from the government due to their sensitive location in the heart of the seat of government. The management and protection of these structures are under the responsibility of the Diwan of Royal Court (DRC) and not the Ministry of Heritage and Culture (MHC), which is officially the responsible body for implementation of the NHPL. All restoration projects that these structures have received since 1970 were made by the DRC.

The current indistinct regulatory mechanism played a substantial role in easing the process of changing the authenticity of the traditional architectural fabric of Old Muscat and, hence, its old defence structures. For instance, despite the fact that the NHPL controls activities that could negatively affect the visual field of the historic monuments [1: Article X], Old Muscat was an exception. Because it is the official place where His Majesty the Sultan receives his visitors, the architectural fabric of Old Muscat underwent drastic changes and many 
simulated defence-like structures have been added to it in the last four decades. The new defence-like buildings, though their designs have been derived from the indigenous defence architecture of the old city, have changed the authenticity and spirit of the place. These replicated defensive structures, such as the small hill towers, the new Gate of Muscat, and the new fortified royal buildings, which were introduced to complement the magnificent scenery of Old Muscat, are manifestations of this changed authenticity. They also denote the special management approach adopted here.

\subsection{Function}

Throughout the world, the issue of the function of old defence sites affects the management of these sites in terms of preservation, conservation, and presentation. The defence structures of Muscat became symbols at the same time that they have lost their original functions. The role assigned to these defence sites today can best be described as minor and decorative. There is a harmony and a conflict between these structures and their surrounding contexts. The question is to what extent the planners have reached a certain degree of harmony between these defence structures and the new architectural fabric that currently surrounds them? Despite the fact that some elements of the newly added buildings are derived from traditional Omani defence architecture, the issue of harmony is still debatable. One must remember that defence structures today do not reflect their status of the past, and their impact has become limited to the fact that they now merely form a visual backdrop of the city; their role has been reduced to be an artistically supplementary component of the cityscape, seascape, and new architectural fabric of the place.

The planners had anticipated that these structures would grant the new city its historic authenticity, but the degree of their success here cannot be gauged easily. Visitors to Muscat today might be engaged by the new architectural components of the place such as the turquoise pillars of the Sultan's magnificent palace, and its surrounding royal governmental buildings. However, although the two forts form the backdrop of the whole scene and overlook the city from a high altitude, their domination of the scene has been reduced.

Moreover, Muscat is not a static city. It has always been exposed to change because of the ever-evolving and dynamic nature of surrounding economic, political, social, environmental, and demographic factors. The inherited defence structures of the city will always remain to testify to its qualities of character and representation. The mono-function of the whole place as a royal quarter influenced the function of the defence structures. Adopting a multi-functional approach in Old Muscat can play a vital role in giving its defence structures new functions and hence augment their attractiveness. It can also help in maintaining the vitality of the place by attracting residents as well as visitors. However, this multi-functionality could bring challenges to the place's identity if it remains uncontrolled. It is very important to preserve the intrinsic value of the place as a space for local people to live. 


\subsection{Accessibility}

The defence structures of Old Muscat enjoy limited public access due to their spatial association with the royal buildings surrounding them, and due to the fact that they are currently operated as military establishments. Unlike the other Omani fortifications which people can visit easily without any administrative difficulty, official permission is needed to access the structures of Old Muscat. There is also a lack of information that would allow the public to better understand them. Apart from their names on very few road signs, no interpretive panels are available to the public and, as a result, people know very little about these structures. Consequently, this has affected people's perception of these structures and, over time, has limited the development of people's personal memories related to these structures. Equitable access to all people is one of the most challenging issues in managing these defence structures, particularly when one considers their sensitive location within the heart of the royal area. The accessibility needed here should encompass not only physical access, but also the accessibility of information and interpretation.

Understanding these structures is a crucial issue in the creation of people's experience. However, making such structures equally accessible to everyone means that some alteration to the structural elements, tangible and intangible, will be inevitable. This alteration is manifested in the city's gates, towers, and walls, which have already lost much of their original shape and many of their original characteristics due to the various processes of rebuilding and conservation that they have been exposed to over the time. Striking a balance between maintaining the authenticity of these structures and the desire to make them accessible will indeed become a real challenge for heritage managers in the future.

\subsection{Competitiveness}

Today, the ability of the defence structures of Old Muscat to compete with newer components of the cityscape is not as strong as before because the attention and consideration which these structures receive from people, heritage managers, and city planners have changed. Despite the fact that these structures have benefited from a number of conservation projects undertaken by the government since the early 1970s, they are no longer the focal point in the urban fabric of the city. The Sultan's Palace and the surrounding new governmental buildings are strong competitors in the scene. The limited accessibility and the mono-function of the whole place also affect their ability to be an integral part of the people's daily life.

The defence sites of Muscat were different in the past from what they now appear to be. Their difference springs from their ever-changing meanings, symbolic values and significance in the people's minds. Their meaning for the new generations is, no doubt, different from that of the people with first-hand memories. The long-term interaction between people and place is vital in the creation of place identity and place attachment. Today, the place is mostly inhabited by the younger generation. The people who remember the life in 
Muscat before 1970 are gone or fast disappearing. Others have long ago left in favour of the new residential areas outside Old Muscat. The weakening bond between the defence structures of Old Muscat and the people who live around it will no doubt play a major role in the end of their attractiveness and competitiveness. Therefore, these structures should form the axial plane of any future design intending to change the urban fabric or to develop this place. Furthermore, the current approaches of their presentation should be revised in a way that strengthens the people's sense of place and hence their preservation.

\subsection{The associated intangible heritage}

The government has allocated and spent a considerable number of resources to the preservation of the defence structures in Old Muscat. However, preserving and conserving these structures is not the end of the story. It is only by preserving the intangible heritage associated with and attached to these structures that we might be able to claim, with some modesty, that we have reached an inclusive and sensible preservation of a part of Muscat's building culture. Many of the stories, myths, folk arts, social practices and events, indigenous knowledge, and memories that are attached to the defence sites of Old Muscat have been wiped out. These intangible elements are associated with and attached to the oral history of the local people who lived here. A glance at the literature written about the history of the defence sites of Muscat is sufficient to reveal that oral history and the other elements of the intangible heritage of the place has been marginalised. These diminishing elements are significant in creating the people's sense of place.

\section{Conclusions}

This study demonstrates that the future of the old defence structures of Old Muscat should be considered in light of the challenges that are confronting them. These relate to development policies, statutory control, management, accessibility, competitiveness, and the function of these structures. In responding to these challenges there is no ready management model to be adopted here. However, treating these structures as an integral part of the life of the place will certainly contribute much to safeguarding them, bringing them to life, and in deepening people's attachment to them.

The collaboration between the defence heritage and urban development in Old Muscat should be reinforced and the conflict should be dealt with in a way sensible to the dynamic natural needs of people and the values they assign to these structures. Clear policies controlling development are necessary to protect these defence structures and to preserve their historicity and authenticity. Policymakers are required to take appropriate actions to manage the change in the historic city of Old Muscat and hence to preserve the intrinsic characteristics of its defence structures. Finally, it should always be remembered that heritage and development both reflect the creativity of human beings and both aim to enhance the quality of people's lives. It is the time to probe the degree of 
interaction between these interrelated efforts and to search for the best ways to manage the conflict and strengthen the balance between them.

\section{References}

[1] Al-Belushi, M.A.K., Managing Oman's Archaeological Resource: Historical Perspectives. Public Archaeology, 7 (3), pp. 150-174, 2008.

[2] Al-Belushi, M.A.K., Oman's Archaeological Heritage: A brief history of its management. Oman-Germany Cultural and Scientific Relations. Symposium Free University of Berlin, ed. F. Scholz, Verlag Hans Schiler: Berlin. ISBN 978-3-89930-270-7, pp. 27-38, 2009.

[3] Salvatory, S., The Prehistoric Graveyard of Ra's Al Hamra 5, Muscat, Sultanate of Oman. The Journal of Oman Studies, 14, pp. 1-353, 2007.

[4] Miles, S.B., The Countries and Tribes of the Persian Gulf. Garnet Publishing: Reading, UK, 1994.

[5] Damluji, S.S., The Architecture of Oman. Garnet Publishing: Reading, UK, 1998.

[6] d'Errico, N., Old Muscat and its Fortifications. In: Damluji, S. S. The Architecture of Oman. Garnet Publishing: Reading, UK, pp. 141-146, 1998.

[7] Costa, G.G., The Ships' Names of Muscat Bay. The Journal of Oman Studies, 7, pp. 105-120, 1985.

[8] Dinteman, W., Forts of Oman. Motivate Publishing: Dubai, Abu Dhabi and London, 1993.

[9] Office of the Deputy Prime Minister for the Ministers Council Affairs, The citadels and forts of Oman, (in Arabic). Publication of Office of the Deputy Prime Minister for the Ministers Council Affairs: Muscat, 1994.

[10] Lorimer, J.G., Gazetteer of the Persian Gulf, Oman and Central Arabia. Garnet: London, 1915, Republished in 1998.

[11] Ministry of National Economy, The 2010 Oman Census Summary. 2012, Online http://85.154.248.117/MONE2010/\#view=viewCensusSummary OmaniExpat\&selectedWafers $=0$ \&selectedColumns $=0$ \&selectedRows $=1$

[12] Strange, I., Planning for change, conserving the past: Towards sustainable development policy in historic cities? Cities, 14 (4), pp. 227-33, 1997.

[13] Royal Decree 6/1980, The Omani national heritage protection law, Official Gazette (in Arabic), Muscat, 1980.

[14] Baker, D., Contexts for Collaboration and Conflict. Managing Historic Sites and Buildings: Reconciling Presentation and Preservation, eds. G. Chitty and D. Baker, Routledge: London and New York, pp. 1-21, 1999.

[15] De Resende, P.B., El Livro do Estado da India Oriental. British Museum, Sloane MS 197 (unpublished manuscript), 1646. 